ISSN 1422-8599

www.mdpi.com/journal/molbank

Short Note

\title{
Theoretical Characterization of Three 2,2-Diphenyl-1,3,2-oxazaborolidin-5-ones: Molecules with Fungicide Activities
}

\author{
Martha Vilchis ${ }^{1,2,3}$, Benjamin Velasco ${ }^{1}$, Guillermo Penieres ${ }^{1}$, Tonatiuh Cruz ${ }^{1}$, René Miranda ${ }^{1,}$ \\ and Inés Nicolás ${ }^{1, *}$ \\ 1 Departamentos de Ciencias Químicas y Ciencias Biológicas, Facultad de Estudios Superiores \\ Cuautitlán Campo 1, Universidad Nacional Autónoma de México, Estado de México, C.P. 54740, \\ México \\ 2 Centro de Bachillerato Tecnológico y de Servicios 160-DGETI-SEP, Cuautitlán México, Estado de \\ México, C.P. 54840, México \\ 3 Departamento de Bioquímica y Sección de Estudios de Posgrado e Investigación, Escuela Superior \\ de Medicina-IPN, México D.F., C.P. 11340, México
}

* Author to whom correspondence should be addressed; E-mail: nicovain@yahoo.com.mx

Received: 17 January 2009 / Accepted: 22 April 2009 / Published: 6 May 2009

\begin{abstract}
In this study, a theoretical characterization for three 2,2-diphenyl-1,3,2oxazaborolidin-5-ones was performed using Density Functional Theory. The analyzed molecules have antifungal activity, making them of particular interest.
\end{abstract}

Keywords: Oxazaborolidinones; DFT; B3LYP

\section{Introduction}

Apoptosis is an important cell death process that is commonly inhibited in cancerous cells [1]. In a different, but sometimes related health threat, fungal infections are emergent diseases with high rates of morbility and mortality in immune-compromised patients. Species of Candida and Aspergillus, as well as Cryptococcus neoformans are among the more frequent infection-causing fungi. Since they 
have very low virulence factors, a reduced immune response is the main predisposing factor for acquiring these infections [2].

In the fields of both apoptosis and fungal infections, much interest is currently focused on boroncontaining molecules, since many compounds with boron-nitrogen bonds have shown insecticidal, antineoplastic, herbicidal, fungicidal, and antibacterial activities [3-6]. In this class of nitrogen-boron coordinated compounds, there is a group that required special attention, the 2,2-diphenyl-1,3,oxazaborolidin-5-ones that are obtained from diphenyl borinic acid and an $\alpha$-amino acid. Recently, we addressed a new method for the production of twelve of these 2,2-dialkyl or 2,2-diphenyl-1,3,2eoxazaborolidin-5-ones [7]. During the course of this investigation, we discovered that the compounds possess cytotoxic activity against two tumor cell lines, one from colon cancer and one from leukemia [1]. In addition, three of these compounds (1-3) have remarkable antifungal activity, Figure 1 and Table 1.

Based on our preliminary findings, and because of the lack of theoretical data for the title compounds 1-3, we conducted a theoretical characterization of the target compounds. We were also interested in pursuing computational methods for molecules of special interest [8-10].

Figure 1. Structure of 2,2-diphenyl-1,3,2-oxazaborolidin-5-ones

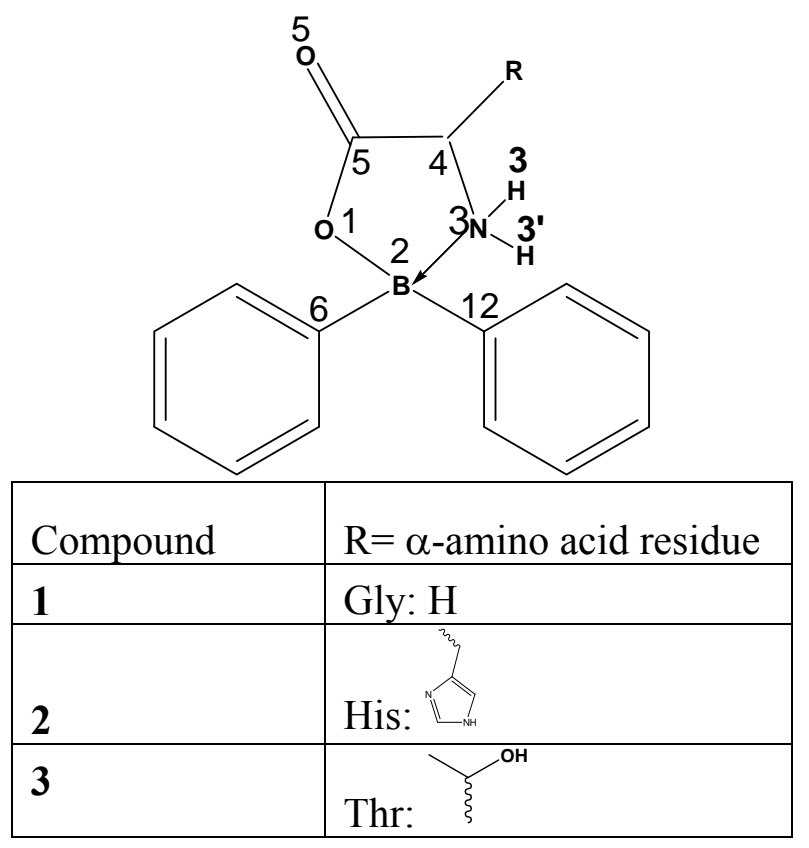

Table 1. Antifungal activity of 2,2-diphenyl-1,3,2-oxazaborolidin-5-ones, 1-3.

\begin{tabular}{|l|l|l|l|l|l|}
\hline Compound* & $\begin{array}{l}\text { Aspergillus } \\
\text { niger 16409 }\end{array}$ & $\begin{array}{l}\text { Cryptococcus } \\
\text { neoformans }\end{array}$ & C.albicans 5609 & $\begin{array}{l}\text { C. parapsilosis } \\
2019\end{array}$ & $\begin{array}{l}\text { C. } \\
6258\end{array}$ \\
\hline $\mathbf{1}$ & +++ & ++++ & +++ & ++++ & ++++ \\
\hline $\mathbf{2}$ & ++ & +++ & ++ & ++ & ++ \\
\hline $\mathbf{3}$ & ++ & +++ & +++ & +++ & +++ \\
\hline
\end{tabular}

*Others $\alpha$-amino acid derivatives presented no activity 


\section{Computational Methodology:}

The modeling of the studied systems was done using the PC program Spartan 02 [11]. Two of the molecules ( 2 and $\mathbf{3}$ ) have a substituent that shows a sp ${ }^{3}$ bond with $\mathrm{C}_{4}$ of the heterocyclic moiety, while $\mathbf{1}$ is unsubstituted. First, a conformational analysis for $\mathbf{2}$ and $\mathbf{3}$ was performed in order to establish the most stable coordinates, using MMFF94s as molecular mechanics [12], implemented in the Spartan 02 program. Next, the molecules (1-3) were optimized using B3LYP/6-311++G(d,p) [13,14], as the level of density functional theory in the Gaussian 03 program [15]. Convergence criteria were set at an energy change of less than $1 \times 10^{-6}$ Hartree and a gradient of less than $3 \times 10^{-4}$ atomics units (a.u.). Vibrational frequencies were calculated on geometry-optimized structures using an analytical Hessian program, and the character of the ground states was confirmed by not imaginary frequencies calculations, performed at the same level.

\section{Results and Analysis}

The three molecules of interest were modeled considering a closed structure. After their optimization, however, they showed an open structure related to the coordinated $\mathrm{H}_{2} \mathrm{~N}---\mathrm{B}$, which is consistent with similar molecules. According to the geometrical parameters, it appears that the bond length between $B_{2} \rightarrow N_{3}$ atoms is short when an amino acid residue is present in position $C_{4}$. Specifically, for these molecules, bond lengths were 1 (1.705 $\AA), 2$ (1.667 $\AA$ ) and 3 (1.682), distances that are consistent with values indicated in the literature (1.638-1.759 $\AA$ ) [16-20]. The dihedral angles did not show significant differences around these atoms, and the bond angles $\left(107^{\circ}\right)$ around the boron atom were approximately tetrahedral. The bond angle between $\mathrm{C}_{6}-\mathrm{B}_{2}-\mathrm{C}_{12}$ atoms was generally more open $\left(117.9^{\circ}\right)$ because of electronic repulsion between the two phenyl groups that causes the bond angle between $\mathrm{O}_{1}-\mathrm{B}_{2}-\mathrm{N}_{3}$ atoms to be more closed, at $97.9^{\circ}$. The bond angles of $\mathrm{C}_{6}-\mathrm{B}_{2}-\mathrm{C}_{12}$ and $\mathrm{O}_{1}-\mathrm{B}_{2}-$ $\mathrm{N}_{3}$ atoms obtained with B3LYP/6-311++G(d,p) were similar to experimental data presented in the literature by HÖpfl et al.[21], at $114.5^{\circ}$ and $99.4^{\circ}$, respectively. According to HÖpfl et al.[22], the large distances observed for the $\mathrm{C}-\mathrm{O}$ atoms of these systems are in agreement with covalent interactions between boron and oxygen atoms.

Our theoretical calculations, evaluated by the scheme of Natural Populations Analysis (NPA), indicated that the boron atom, $\mathrm{B}_{2}$, was very polarized, with an average value of $0.873 \mathrm{e}^{-}$, whereas the oxygen atom, $\mathrm{O}_{1}$, showed an average value of $-0.684 \mathrm{e}^{-}$, and the nitrogen atom, $\mathrm{N}_{3}$, had a value of $0.758 \mathrm{e}^{-}$. In addition, for the $\mathrm{C}_{4}$ substituted compounds (2-3), the nitrogen atom, $\mathrm{N}_{3}$, presented a more negative value. The boron atom became less positive, a feature assigned to an electronic gain coming from the oxygen atom $\mathrm{O}_{1}$. At the same time, the carbon atoms $\mathrm{C}_{4}$ and $\mathrm{C}_{5}$ displayed a charge decrease. For $\mathrm{C}_{5}$, the decrease in charge can be explained by the increased polarization of the $\mathrm{O}_{5}$ atom. The hydrogen atom $\mathrm{H}_{3}$ ' of molecule 2 exhibited a greater electronic deficiency because of intramolecular interaction with the nitrogen atom of the amino acid residue ring that is located at a distance of 1.997 A. In molecule 3, this interaction was between hydrogen atom $\mathrm{H}_{3}$ and the oxygen atom of the amino acid residue, and had a distance of $1.128 \AA$.

According to the Lowest Unoccupied Molecular Orbital (LUMO) contour plots determinated for each compound, only molecule $\mathbf{1}$ had a great electronic deficiency. In addition, for evaluated molecules 1-3, the corresponding Highest Occupied Molecular Orbitals (HOMO) contour plots were 
mainly distributed around the $\pi$ bonds of the phenyl groups. Additionally, mapping the electrostatic potential displayed a greater electronic deficiency for molecule $\mathbf{1}$, while in $\mathbf{2}$ and $\mathbf{3}$, because of intramolecular interactions, this effect was diminished. Finally, the thermodynamic properties of 1-3 molecules in Figure 1, were calculated at the B3LYP/6-311++G(d,p) level of theory. A recent literature search found no experimental data on these properties.

\section{Conclusions}

In the current study, the distance between $\mathrm{B}_{2} \rightarrow \mathrm{N}_{3}$ atoms of the presented 2,2-diphenyl-1,3,2oxazaborolidin-5-ones was demonstrated to be modified by the amino acid residue on $\mathrm{C}_{4}$. This residue also modifies the charges of the heterocyclic atoms. The intramolecular interactions changed several molecular properties, including the charge of hydrogen atoms, $\mathrm{H}_{3} / \mathrm{H}_{3}$, and the LUMO contours.

\section{Acknowledgements}

Financial support from PACIVE: VIASC-103 and Catedras de Investigation: IN1-46 from FESCUNAM. Access to the Kan Balam supercomputer at DGSCA-UNAM is fully appreciated; M.B. Vilchis to CoSNET for the corresponding schoolarship 02004217C.

\section{References and Notes}

1. Velasco, B.; Trujillo-Ferrara, J.G.; Fabila-Castillo L.H.; Miranda, R.; Sanchez-Torres, L.E. In vitro apoptotic activity of 2,2-diphenyl-1,3,2-oxazaborolidin-5-ones in L5178Y cells. Life Sci. 2007, 80, 1007-1013.

2. Anaissie, E.J. Clinical Mycology; Churchill Livingstone: Philadelphia, 2003; pp.195-239.

3. Groziak, M.P. Boron therapeutics on the horizons. Am. J. Therapeutics. 2001, 8, 321-328.

4. Dobrydneva, Y.; Abelt, C.J.; Dovel, B.; Thadigiri, C.M.; Williams, R.L.; Blackmore, P.F. 2Aminoethoxydiphenyl borate as a prototype drug for a group of structurally related calcium channel blockers in human platelets. Mol. Pharmacol. 2006, 69, 247-256.

5. Flückiger, R.; Henson, E.; Hess, G.; Gallop, P. Mass spectral and HPLC analysis of biological compounds with diphenylborinic acid. Biomed. Mass Specrometry. 1984, 11, 611-615.

6. Strang, C.J.; Henson E.; Okamoto, Y.; Paz, M.A.; Gallop, P.M. Separation and determination of $\alpha$-amino acids by boroxazolidones formation. Analit. Biochem. 1989, 178, 276-286.

7. Velasco-Bejarano, B.; Trujillo-Ferrara, J.G.; Miranda, R. Preparation of apoptotic inducers 2,2diphenyl-1,3,2-oxazaborolidin-5-ones under alkaline conditions. SYNLETT, 2007, 6, 921-924.

8. Nicolás, I.; Vilchis, M. B.; Aragón, N.; Miranda, R.; Hojer, G. A.; Castro, M. Theoretical study of the structure and antimicrobial activity of horminone. Int. J. Quantum Chem. 2003, 93, 411-421.

9. Nicolás, I.; Castro, M. Theoretical study of the complexes of horminone with $\mathrm{Mg}^{2+}$ and $\mathrm{Ca}^{2+}$ ions and their relation with the bacteriostatic activity. J. Phys. Chem. A 2006, 110, 4564-4573.

10. Méndez-Albores, A.; Nicolás-Vázquez, I.; Miranda-Ruvalcaba, R.; Moreno-Martínez, E. Mass spectrometry/mass spectrometry study on the degradation of B-aflatoxins in maize with aqueous citric acid lactonic moiety. Am. J. Agril. \& Biol. Sci. 2008, 3, 482-489.

11. Deppmeier, B.J.; et al., Spartan '02, Wavefunction Inc., Irvine CA. 2001. 
12. Hehre, W. J.; A Guide to Molecular Mechanics \& Quantum Chemical Calculations, Wavefunction, Inc.: Irvine, CA, USA, 2003, pp. 61-88.

13. Becke, A.D. Density-functional thermochemistry. III. The role of exact exchange. J. Phys. Chem. 1993, 98, 5648-5652.

14. Lee, C.; Yang, W.; Parr, R.G. Development of the Colle-Salvetti correlation-energy formula into a functional of the electron density. Phys. Rev. B. 1988, 37, 785-789.

15. Frisch, M. J.; et al., Gaussian 03, Revision D.01, Gaussian, Inc., Wallingford CT, 2004.

16. Farfán, N.; Joseph-Nathan, P.; Chiquete, L.M.; Contreras, R. Syntheses and structures of two new dibenzobicyclic phenylboronates. J. Organomet. Chem. 1988, 348, 149-156.

17. Farfán, N.; Mancilla, T.; Castillo, D.; Uribe, G.; Carrillo, L.; Joseph-Nathan, P.; Contreras, R. NMR and X-ray diffraction studies of two bicyclic borates containing chiral boron and nitrogen atoms. J. Organomet. Chem. 1990, 381, 1-13.

18. Farfán, N.; Castillo, D.; Joseph-Nathan, P.; Contreras, R.; Szentpály, L.V. Through-bond modulation of $\mathrm{N} \rightarrow \mathrm{B}$ ring formation shown by NMR and X-ray diffraction studies of borate derivatives of pyridyl alcohols. J. Chem. Soc., Perkin Trans. 2, 1992, 527-532.

19. Toyota, S.; Oki, M. Structure of intramolecular boron-amine complexes and proposal of tetrahedral character for correlation between molecular structure and barrier to the N-B bonds. Bull Chem. Soc. Jpn. 1992, 65, 1832-1840.

20. Kliegel, W.; Lubkowitz, G.; Rettig, S.J.; Trotter, J. Structural studies of organoboron compounds. XLIX 4, 6-Bis(1-phenyl-2-nitroethyl)-2-(4-methoxyphenyl)-1,3-dioxa-4,6-diaza-2boracyclohexane. Can. J. Chem. 1991, 69, 1227-1232.

21. HÖpfl, H.; Farfán, N.; Castillo, D.; Santillan, R.; Contreras, R.; Martínez-Martínez, F. J.; Galván M.; Alvarez, R.; Fernández, L.; Halut, S.; et al. Dynamic NMR and X-ray diffraction study of (NB) -diphenyl(2-aminoethoxy) borane derivatives of ephedrines, and pseudoephedrines $J$. Organomet. Chem. 1997, 544, 175-188.

22. HÖpfl, H.; Pérez, N.; Rojas, S.; Santillan, R.; Farfán, N. X-ray crystallographic study of neutral boron chelates with $b$-diketones and tropolone. Heteroat. Chem., 1998, 9, 359-368.

(C) 2009 by the authors; licensee Molecular Diversity Preservation International, Basel, Switzerland. This article is an open-access article distributed under the terms and conditions of the Creative Commons Attribution license (http://creativecommons.org/licenses/by/3.0/). 